\section{Modelling \\ postoperative visual acuity with and without proliferative vitreoretinopathy associated with primary \\ rhegmatogenous retinal detachment}

M Roldán-Pallarés',2, C Bravo-Llatas³, A-S Musa ${ }^{1,2}$, $J$ Hernandez-Montero ${ }^{4}$ and R Fernández-Durango ${ }^{5}$

\author{
Abstract \\ Purpose To find models that will explain \\ the variability in postoperative visual acuity \\ (VA) (logarithmic: logMAR) associated \\ with unilateral primary rhegmatogenous \\ retinal detachment (RD). \\ Methods This was a prospective clinical \\ cohort study of 33 patients with proliferative \\ vitreoretinopathy (PVR: PVR $<$ C3) and 33 \\ without PVR, all of whom were candidates \\ for scleral buckling (SB) surgery. Central \\ retinal artery (CRA) Doppler sonography \\ parameters (peak systolic, end diastolic \\ velocities and resistibility index) and \\ intraocular pressure (IOP) were measured \\ before SB. Immunoreactive endothelin-1 \\ (IR-ET-1) levels in both plasma and \\ subretinal fluid (SRF) were measured using a \\ radioimmunoassay. Visual outcomes were \\ analysed by stepwise multivariate linear \\ regression. The preoperative parameters used \\ in the analysis included RD duration, IOP, \\ logMAR VA, CRA parameters, preoperative \\ plasma levels and intraoperative levels of \\ IR-ET-1 in the SRF. \\ Results The models for 8-month- \\ postoperative logMAR VA demonstrated a \\ predictive power higher than $85 \%$. The \\ values of the 8-month-postoperative \\ logMAR VA were as follows: (a) in No \\ PVR $=-0.151+0.06$ preoperative duration \\ (days), with a predictive power of $85.3 \%$; \\ (b) in PVR $=-1.071+0.06$ SRF IR-ET-1 \\ $(\mathrm{pg} / \mathrm{ml})+0.459$ preoperative $\log$ MAR VA \\ explaining $89.9 \%$ of the variability in the \\ postoperative logMAR VA.
}

Conclusions The duration of RD and the levels of IR-ET-1 in the SRF appear to be the best explanatory variables in the models for 8-month-postoperative logMAR VA variability in RD patients. RD surgery should be performed as soon as possible to best preserve VA.

Eye (2012) 26, 1329-1336; doi:10.1038/eye.2012.153; published online 10 August 2012

Keywords: retinal detachment; preoperative duration; immunoreactive endothelin-1; linear regression models; logarithmic visual acuity; proliferative vitreoretinopathy

\section{Introduction}

Proliferative vitreoretinopathy (PVR) is the most common cause of treatment failure in rhegmatogenous retinal detachment (RD) and is often associated with unsatisfactory visual outcomes. ${ }^{1,2}$ The duration of RD before surgical intervention and the presence of PVR have been reported to be associated with worse preoperative and postoperative visual acuity (VA). ${ }^{3}$

Eshita et l $^{4}$ reported reduced retinal blood flow compared with normal controls in the macular area of eyes with RD and no macular involvement. We have previously reported reduced preoperative central retinal artery (CRA) ${ }^{5}$ and ophthalmic artery (OA) blood flows, ${ }^{6}$ as well as reduced intraocular pressure $(\mathrm{IOP})^{7}$ in the eyes with RD and PVR compared with normal eyes. RD may lower IOP by inducing inflammation and reducing aqueous
${ }^{1}$ Department of Ophthalmology, Medical School, Complutense University, Madrid, Spain

${ }^{2}$ Ophthalmology Service, Hospital Clínico San Carlos, Madrid, Spain

${ }^{3}$ Computational Service, Complutense University, Madrid, Spain

${ }^{4}$ Radiology Service, Hospital Clínico San Carlos, Madrid, Spain

${ }^{5}$ Research Unit, Internal Medicine III Service, Hospital Clínico San Carlos, Madrid, Spain

Correspondence: M Roldán-Pallarés, Department of Ophthalmology, Medical School, Complutense University, Rey Francisco 11, $3^{\circ}, 28008$ Madrid, Spain Tel: +34 9154778 85; Fax: +34 913303961 . E-mail: MRPUCMHS@ telefonica.net

Received: 11 May 2011 Accepted in revised form: 6 July 2012 Published online: 10 August 2012 
humour formation. ${ }^{8}$ Reitsamer and $\mathrm{Kiel}^{9}$ found that aqueous humour production was dependent on ciliary body blood flow, when the flow was reduced below $74 \%$ of its normal value.

Previously, we reported ${ }^{10}$ parameters that were influenced by preoperative duration of RD. These included preoperative CRA parameters, preoperative IOP, the preoperative logarithm of the minimum angle of resolution (logMAR) and the 8-month-postoperative logMAR. These parameters were influenced by preoperative RD duration in patients with and without PVR.

The endothelin (ET) system is an important modulator of retinal, ${ }^{11}$ optic nerve head, and choroidal blood flows. ${ }^{12,13}$ Endothelin-1 (ET-1) is a potent vasoconstrictor that may cause hypoperfusion of the neurosensory retina. ${ }^{14}$ Ischaemia-reperfusion of the rabbit retina has been reported to cause exudative RD with a loss of photoreceptor cells. Micro- and macroglial cells were found to be activated early in reperfusion, even before the dropout of the photoreceptor cells. ${ }^{15}$ Gliosis may contribute to neural degeneration, explaining the impaired recovery of vision observed in human subjects after retinal reattachment surgery. ${ }^{16}$ Higher immunoreactive (IR) ET-1 levels were reported by our group in the eyes with RD complicated by PVR. Moreover, ET-1 is secreted by glial and RPE cells, and ETA and ETB receptors are expressed in epiretinal proliferative tissue. ${ }^{17}$ In our study, IR-ET-1 levels in the subretinal fluid (SRF) were more strongly associated with PVR (as a complication of RD) than with the preoperative duration of RD. ${ }^{18}$

The purpose of this paper was to quantify the influence of several factors in predicting VA (expressed as logMAR) 8 months after surgery in patients who had primary rhegmatogenous RD with or without PVR. Factors analysed in this study included (1) the preoperative duration of RD (in days), (2) the preoperative logMAR of VA, (3) the preoperative ocular haemodynamics (in terms of CRA Doppler parameters), (4) the preoperative IOP, and (5) the ET-1 levels in both plasma and SRF.

\section{Materials and methods}

A prospective clinical cohort study in accordance with the principles embodied by the Declaration of Helsinki was conducted after approval from our institutional clinical research committee. Informed consent was obtained from patients after the nature of the study was explained.

\section{Participants}

Our previous clinical experience showed a mean change in the best-corrected vision (expressed in terms of $\log$ MAR VA) of 0.30 after 8 months of follow-up (with a mean SD of 0.30 ) after $360^{\circ}$ scleral buckling (SB) surgery for RD in patients with and without PVR. On the basis of these findings, we determined that 32 eyes in each group would be necessary to obtain significant differences with a study power of 0.90 at a significance level of $P=0.01$.

Therefore, 100 patients—50 with PVR and 50 without PVR-were prospectively and consecutively selected according to the study's inclusion/exclusion criteria between 1 July 2004 and 1 July 2008. During the same time period, a total of 1586 RD cases (1074 No PVR and 512 PVR) arrived at our hospital for emergent care and/ or in response to referrals. A total of 1486 (1024 No PVR and 462 PVR) cases were excluded because they met one or more of the exclusion criteria.

The inclusion criteria were as follows: (1) an age between 42 and 70 years; (2) mean arterial blood pressure (MAP) $\leq 105 \mathrm{~mm} \mathrm{Hg}$; (3) unilateral rhegmatogenous $\mathrm{RD}$, with an extension $\geq 2$ quadrants and visible tears; (4) best-corrected preoperative ETDRS VA (Early Treatment Diabetic Retinopathy Study) measured as logMAR VA $\leq 1$ (based on the results of a Lighthouse Distance Visual Acuity Test, Chart 2; Lighthouse International, New York, NY, USA); (5) IOP $\leq 16 \mathrm{~mm} \mathrm{Hg}$ (and no known IOP alterations); (6) previously reported refractive error $\leq 3$ dioptres (spheric and/or cylinder); (7) no systemic or other ocular diseases; (8) no evidence of macular disease (Stratus OCT) other than macular detachment, and (9) qualification for $360^{\circ} \mathrm{SB}$ surgery (PVR $\leq \mathrm{C} 3$ ) as a first and single surgical procedure. Preoperative PVR was graded according to the Retinal Society Classification. ${ }^{19,20}$ For inclusion in the results, the retinas of patients included in the study were required to remain attached throughout the study followup period of 8 months.

The exclusion criteria were as follows: (1) an age of $<42$ or $>70$ years; (2) PVR >C3 (in these cases vitrectomy is indicated); (3) retinal dialysis or giant retinal tears; (4) an extension of $\mathrm{RD}<2$ quadrants; (5) no visible tears; (6) MAP >105 $\mathrm{mm} \mathrm{Hg}$; (7) best-corrected logMAR VA > 1 ; (8) IOP > $16 \mathrm{~mm} \mathrm{Hg}$; (9) previous reported refractive error $>3 \mathrm{D}$; (10) blunt trauma affecting the eye within the last 6 months; (11) evidence of macular disease including vitreo-macular traction, epiretinal membranes, cystoid macular oedema, RPE changes, or age-related macular degeneration (Stratus OCT); (12) concurrent eye conditions such as infection, intraocular eye surgery, surgical cataract repair, intraocular bleeding, aphakia, pseudophakia, and previous RD; (13) the use of topical ocular therapy; (14) patients with cardiovascular, haematological and metabolic disorders, or who were receiving any systemic treatment were also excluded; (15) blood contamination of SRF samples during the surgical drainage procedure was considered a reason for exclusion because this might 
alter the ET-1 measurements; (16) finally, if repeat RD, surgical cataract, and/or intraocular bleeding appeared during the 8-month follow-up period, the case was excluded.

Thirty-four of the initially selected RD patients $(n=100)$ were ultimately excluded. Six patients were excluded for blood contamination of SRF samples during the surgical drainage procedure. During the follow-up period 4 patients suffered retinal redetachment, 2 developed cataracts that required surgery, 1 had intraocular bleeding, 18 showed OCT changes (14 developed epiretinal membranes, 1 had cystoid macular oedema, 2 had RPE changes, and 1 had persistent submacular fluid). Two patients were lost to follow-up, and one patient did not return for the last follow-up visit. A total of 66 healthy patients (42-70 years of age) with unilateral primary rhegmatogenous RD (33 with PVR and 33 without PVR) were studied. The mean preoperative $\mathrm{RD}$ duration was $5.94 \pm 3.15$ days, the preoperative best-corrected $\log \mathrm{MAR}$ VA $\leq 1$, the preoperative IOP was $\leq 16 \mathrm{~mm} \mathrm{Hg}$, the preoperative MAP was $\leq 105 \mathrm{~mm} \mathrm{Hg}$, and the preoperative reported refractive error was $\leq 3 \mathrm{D}$. The retina was reattached after SB surgery, which was always performed by the same surgeon. After 8 months of follow-up, a final bestcorrected $\log$ MAR VA was obtained between March 2005 and February 2009.

\section{Observation procedures and outcome measures}

Patients underwent complete ophthalmological examinations by two different ophthalmologists, with more than 10 years experience each in retinal pathologies. The kappa index between the two physicians' observations was $>0.75$, before RD surgery. Routine clinical follow-up was performed at 1 week, and at 1,3 , and 6 months after surgery. The MAP was calculated by averaging the systolic and diastolic blood pressures measured on the upper arm between 0700 hours and 0900 hours on the day of surgery. At that time, patients were asked to report the interval in days from the start of their symptoms. The $6 \times 6 \mathrm{~mm}$ radial line scan protocol was performed on each patient using a Stratus OCT model 3000 scanner (Zeiss Humphrey Instruments, Dublin, CA, USA) on the day before surgery and 3 months after surgery. The best-corrected logMAR VA and retinal status were recorded on the day before and 8 months after surgery.

CRA blood flow parameters were always measured, as previously described, ${ }^{5,10}$ with patients in the dorsal decubitus position. CRA blood flow measurements were taken the day before surgery, always at the same time of day (between 1800 hours and 2000 hours). A colourDoppler ultrasound device (Sonolayer SSH-140A;
Toshiba Medical Systems, Hammfelddamm, Neus, Germany) with a linear transducer at a nominal imaging frequency of $7.5 \mathrm{MHz}$ was used, as has been previously reported in detail. ${ }^{21,22}$ The optic nerve was identified using a B-scan ultrasound. Using the colour Doppler, the CRA was identified over the head of the optic nerve. The peak systolic velocity (PSV) and end-diastolic velocity (EDV) were measured (in centimetres per second) from the timed velocity waveforms of the CRA. Two different radiologists performed the technique twice such that the average value of each velocity could be considered in the study. Agreement between these two physicians was close, with an intraclass correlation coefficient $>0.75$. The resistibility index (RI) was calculated by the formula $\mathrm{RI}=(\mathrm{PSV} / \mathrm{EDV}) / \mathrm{PSV}$.

Venous blood samples $(10 \mathrm{ml})$ were obtained before the induction of anaesthesia for the SB surgery. SRF was obtained during the drainage procedure of the RD surgery, ${ }^{23}$ as previously reported. ${ }^{18,24}$ Briefly, after a 1-mm sclerotomy and local diathermic coagulation of the choroids at the site of maximum prominence of the detached retina, a plastic disposable fine-tip transfer pipet (Life Scan Inc., Milpitas, CA, USA) was used to obtain the SRF. Both SRF and blood samples were collected in chilled tubes containing protease inhibitors. $6,17,18$ Blood samples were centrifuged at 3000 r.p.m. for $20 \mathrm{~min}$ at $4{ }^{\circ} \mathrm{C}$ to obtain plasma. SRF samples were centrifuged at 13000 r.p.m. for $15 \mathrm{~min}$ at $4{ }^{\circ} \mathrm{C}$. The supernatants were stored at $-70{ }^{\circ} \mathrm{C}$ for $<3$ months before testing.

The ET-1 extraction was performed with a Sep-Pack C18 cartridge (Waters Associates, Milford, MA, USA). IR-ET-1 measurements were taken from plasma and SRF samples as previously reported. 6,17,18,24 Briefly, IR-ET-1 was assayed in the laboratory by RIA, using polyclonal antibodies against synthetic ET-1 (Peninsula Laboratories, Merseyside, UK) at a 1:90000 final dilution. The sensitivity of the RIA was $1 \mathrm{pg} / \mathrm{ml}$. The $50 \%$ intercept was $50 \mathrm{pg} / \mathrm{ml}$. The interassay variation was $13 \%$ and the intra-assay variation was $10 \%$. Recoveries associated with additions of 1.5 and 3 pg of ET- 1 to pooled vitreous fluid were $78 \pm 3.2 \%(n=10)$.

\section{Statistical analyses}

Results are presented as means \pm SD. Statistical evaluations consisted of the $\chi^{2}$ test, Fisher's exact test, the Student's $t$-test, and Pearson correlation coefficients. Stepwise multivariate linear regression analysis with SPSS (Statistical Package for the Social Sciences; version 17, SPSS Inc., Chicago, IL, USA) was used to identify models for postoperative logMAR VA (at 8 months) in patients with and without PVR. The explanatory variables considered were as follows: preoperative RD 
duration, preoperative IOP, preoperative logMAR VA, preoperative plasma IR-ET-1, intraoperative SRF IRET-1, preoperative CRA PSV, preoperative CRA EDV, preoperative CRA RI, and the presence or absence of preoperative PVR. The interactions between the presence of PVR and all other explanatory variables were studied. Stepwise multivariate linear regression analysis was also performed for RD patients with and without PVR. The predictive power of models was given by the determination coefficient $\left(R^{2}\right)$. The predictive power (ie, the determination coefficient or $R^{2}$ ) refers to the proportion of postoperative logMAR VA variability that is explained by the variables included in the model.

Model-checking assumptions were tested and successfully verified. Regression collinearity (the correlation between independent variables) and case-wise diagnostics were performed to prevent multicollinearity and to identify influential cases. Maple 12 (Maplesoft, Waterloo Maple Inc., Waterloo, ON, Canada) was used for 3D-plots and graphics.

\section{Results}

The mean values of the variables included in the study are provided in Table 1 . Thirty-four $(51.52 \%)$ of our patients were men, and $32(48.48 \%)$ were women. No statistically significant differences in age (by a $t$-test), sex (by $\chi^{2}$ and Fisher's exact tests), and/or MAP (by a $t$-test) were found between patients with and without PVR. Age did not influence logMAR VA measurements in either patients with PVR or patients without PVR (Pearson's correlation coefficients were not significant). Table 2 shows the quantitative correlations $\left(r^{2}\right.$ : determination coefficients) between the preoperative duration (days) of $\mathrm{RD}$ and the variables considered in our study in patients with and without PVR.

There was a significant interaction $(P<0.0001)$ between PVR and the other explanatory variables for postoperative VA (expressed in terms of the 8-monthpostoperative logMAR). An excessive correlation between independent variables (collinearity) made it difficult or impossible to assess the relative importance of the predictive variables identified when PVR was included in the models $(n=66)$. This finding suggests that different models should be constructed for patients with and without PVR. Table 3 shows the explanatory variables of the postoperative VA (obtained through stepwise multivariate linear regression analysis) in patients with and without PVR.

Table 4 shows comparative postoperative VA mean values (obtained at 8 months), when the independent variables included in the models were categorised by median values.

\section{Postoperative (8 months) VA Models}

Patients without PVR In this group of RD patients, postoperative VA was explained by the preoperative

Table 2 Quantitative correlations between preoperative duration of retinal detachment and the variables of the study in No PVR and PVR

\begin{tabular}{|c|c|c|}
\hline Variables & No PVR $(\mathrm{n}=33)$ & $P V R(\mathrm{n}=33)$ \\
\hline Duration preop (days) & $4.27 \pm 2.43$ & $7.61 \pm 3.88$ \\
\hline IOP preop $(\mathrm{mm} \mathrm{Hg})$ & $r^{2}=0.6306$ & $r^{2}=0.6829$ \\
\hline \multirow[t]{2}{*}{ LogMAR preop } & $r^{2}=0.6018$ & $r^{2}=0.1585$ \\
\hline & $\boldsymbol{P}<0.0001$ & $P=0.0217$ \\
\hline \multirow[t]{2}{*}{ LogMAR postop (8 months) } & $r^{2}=0.5483$ & $r^{2}=0.1933$ \\
\hline & $\boldsymbol{P}<0.0001$ & $\boldsymbol{P}=0.0105$ \\
\hline \multirow[t]{2}{*}{ LogMAR diff } & $r^{2}=0.0352$ & $r^{2}=0.0271$ \\
\hline & $\boldsymbol{P}=0.296$ & $\boldsymbol{P}=0.3611$ \\
\hline \multirow[t]{2}{*}{ CRA PSV preop (cm/s) } & $r^{2}=0.5666$ & $r^{2}=0.4286$ \\
\hline & $P<0.0001$ & $P<0.0001$ \\
\hline \multirow[t]{2}{*}{ CRA EDV preop $(\mathrm{cm} / \mathrm{s})$} & $r^{2}=0.5499$ & $r^{2}=0.4759$ \\
\hline & $P<0.0001$ & $P<0.0001$ \\
\hline \multirow[t]{2}{*}{ CRA RI preop } & $r^{2}=0.5104$ & $r^{2}=0.4331$ \\
\hline & $P<0.0001$ & $P<0.0001$ \\
\hline \multirow[t]{2}{*}{ Plasma IR-ET-1 (pg/ml) } & $r^{2}=0.2136$ & $r^{2}=0.0386$ \\
\hline & $\boldsymbol{P}=0.0068$ & $\boldsymbol{P}=0.2731$ \\
\hline \multirow[t]{2}{*}{ SRF IR-ET-1 (pg/ml) } & $r^{2}=0.1573$ & $r^{2}=0.103$ \\
\hline & $\boldsymbol{P}=0.0223$ & $P=0.0685$ \\
\hline
\end{tabular}

Table 1 Mean values of the variables of the study in the No PVR and PVR groups with regard to macular detachment

\begin{tabular}{|c|c|c|c|c|c|c|c|c|c|}
\hline \multirow[t]{2}{*}{ Groups and variables } & \multicolumn{3}{|c|}{ No PVR } & \multicolumn{5}{|c|}{$P V R$} & \multirow{2}{*}{$\begin{array}{c}\mathrm{t} \text {-test } \\
\mathrm{P}(1-4)\end{array}$} \\
\hline & $\begin{array}{l}\text { (1) Total } \\
\text { group: } \\
\mathrm{n}=33\end{array}$ & $\begin{array}{c}\text { Macula-on: } \\
\mathrm{n}=25\end{array}$ & $\begin{array}{l}\text { Macula-off: } \\
\mathrm{n}=8\end{array}$ & $\begin{array}{c}\mathrm{t} \text {-test } \\
P(2-3)\end{array}$ & $\begin{array}{l}\text { (4) Total } \\
\text { group: } \\
\mathrm{n}=33\end{array}$ & $\begin{array}{c}\text { Macula-on: } \\
\mathrm{n}=11\end{array}$ & $\begin{array}{c}\text { Macula-off: } \\
\mathrm{n}=22\end{array}$ & $\begin{array}{c}\mathrm{t} \text {-test } \\
\mathrm{P}(5-6)\end{array}$ & \\
\hline Age (years) & $56.39 \pm 6.86$ & $55.72 \pm 6.59$ & $58.51 \pm 7.75$ & 0.4471 & $57.31 \pm 5.88$ & $56.18 \pm 5.47$ & $57.86 \pm 6.11$ & 0.3265 & 0.5653 \\
\hline MAP preop (mm Hg) & $94.61 \pm 5.24$ & $94.31 \pm 6.13$ & $94.89 \pm 4.35$ & 0.3184 & $95.82 \pm 3.36$ & $95.66 \pm 3.59$ & $95.98 \pm 3.13$ & 0.2197 & 0.4952 \\
\hline Duration preop (days) & $4.27 \pm 2.43$ & $3.12 \pm 0.93$ & $7.88 \pm 2.11$ & 0.0096 & $7.61 \pm 3.88$ & $4.45 \pm 0.93$ & $9.18 \pm 3.84$ & 0.0006 & 0.0001 \\
\hline IOP preop (mm Hg) & $11.07 \pm 0.88$ & $11.45 \pm 0.48$ & $9.91 \pm 0.85$ & 0.035 & $9.97 \pm 1.18$ & $11.02 \pm 0.83$ & $9.45 \pm 0.98$ & 0.003 & 0.0001 \\
\hline LogMAR postop (8 months) & $0.13 \pm 0.22$ & $0.04 \pm 0.05$ & $0.42 \pm 0.31$ & 0.0089 & $0.36 \pm 0.31$ & $0.27 \pm 0.29$ & $0.41 \pm 0.31$ & 0.2509 & 0.0009 \\
\hline LogMAR diff & $-0.34 \pm 0.16$ & $-0.31 \pm 0.08$ & $-0.43 \pm 0.31$ & 0.3075 & $-0.31 \pm 0.25$ & $-0.23 \pm 0.17$ & $-0.35 \pm 0.28$ & 0.1325 & 0.6155 \\
\hline CRA PSV preop $(\mathrm{cm} / \mathrm{s})$ & $11.06 \pm 0.12$ & $11.11 \pm 0.07$ & $10.89 \pm 0.06$ & $<0.0001$ & $10.17 \pm 0.78$ & $10.41 \pm 0.81$ & $10.06 \pm 0.75$ & 0.3827 & $<0.0001$ \\
\hline CRA EDV preop $(\mathrm{cm} / \mathrm{s})$ & $3.89 \pm 0.14$ & $3.95 \pm 0.07$ & $3.68 \pm 0.07$ & $<0.0001$ & $3.31 \pm 0.37$ & $3.47 \pm 0.42$ & $3.21 \pm 0.32$ & 0.0561 & $<0.0001$ \\
\hline CRA RI preop & $0.58 \pm 0.008$ & $0.58 \pm 0.006$ & $0.59 \pm 0.001$ & $<0.0001$ & $0.62 \pm 0.04$ & $0.61 \pm 0.04$ & $0.63 \pm 0.04$ & 0.3545 & $<0.0001$ \\
\hline Plasma IR-ET-1 (pg/ml) & $2.62 \pm 0.31$ & $2.53 \pm 0.31$ & $2.89 \pm 0.16$ & 0.0034 & $3.22 \pm 0.34$ & $3.32 \pm 0.31$ & $3.17 \pm 0.35$ & 0.2338 & $<0.0001$ \\
\hline SRF IR-ET-1 (pg/ml) & $3.21 \pm 0.72$ & $2.99 \pm 0.61$ & $3.91 \pm 0.63$ & 0.001 & $18.21 \pm 3.46$ & $18.65 \pm 3.93$ & $17.99 \pm 3.28$ & 0.6117 & $<0.0001$ \\
\hline $\begin{array}{l}\text { SRF-Plasma IR-ET-1 diff } \\
(\mathrm{pg} / \mathrm{ml})\end{array}$ & $0.59 \pm 0.56$ & $0.46 \pm 0.51$ & $1.01 \pm 0.55$ & 0.012 & $14.99 \pm 3.22$ & $15.33 \pm 3.68$ & $14.81 \pm 3.05$ & 0.6689 & $<0.0001$ \\
\hline
\end{tabular}


Table 3 Explanatory variables of visual acuities in No PVR and PVR groups of retinal detachment

\begin{tabular}{llrr}
\hline $\begin{array}{l}\text { Models for } \\
(\mathrm{n})\left(\mathrm{R}^{2}, \mathrm{P}-\text {-value }\right)\end{array}$ & $\begin{array}{l}\text { Intercepts and } \\
\text { independent variables }\end{array}$ & Coefficients & Significance \\
\hline LogMAR VA postoperative in No PVR $(32)(0.853,<0.0001)$ & Intercept & $-0.151(0.022)$ \\
& Duration (days) & $0.06(0.005)$ & 0.0001 \\
LogMAR VA postoperative in PVR $(31)(0.899,<0.0001)$ & Intercept & $-1.071(0.091)$ & $0.06(0.005)$ \\
& SRF IR-ET-1 (pg/ml) & 0.0001 \\
& LogMAR VA preoperative & $0.459(0.075)$ & 0.0001 \\
\hline
\end{tabular}

Table 4 Comparative postoperative 8-month visual acuity means in the groups No PVR and PVR of retinal detachment

\begin{tabular}{|c|c|c|c|c|}
\hline Model for (n) & \multicolumn{2}{|c|}{$\begin{array}{l}\text { Independent variables included in the model categorised } \\
\text { by median values }\end{array}$} & $\begin{array}{l}\text { Postoperative } \\
\text { 8-months } \\
\log M A R V A \\
\text { media } \pm S D\end{array}$ & $\begin{array}{l}\text { Significance } \\
\text { Student T-test }\end{array}$ \\
\hline \multirow{6}{*}{$\begin{array}{l}\text { LogMAR VA postoperative in No PVR } \\
(\mathrm{n}=32) \\
\text { LogMAR VA postoperative in PVR } \\
(n=31)\end{array}$} & \multirow[t]{2}{*}{ Duration (in days, $n$ ) } & $\leq 3,17$ & $0.022 \pm 0.029$ & \multirow{3}{*}{0.0038} \\
\hline & & $>3,15$ & $0.21 \pm 0.19$ & \\
\hline & \multirow[t]{2}{*}{ SRF IR-ET-1 (in pg/ml, $n$ ) } & $\leq 16.6,15$ & $0.19 \pm 0.16$ & \\
\hline & & $>16.6 \mathrm{pg} / \mathrm{ml}, 16$ & $0.47 \pm 0.31$ & 0.0036 \\
\hline & \multirow[t]{2}{*}{ LogMAR VA preoperative (value, $n$ ) } & $\leq 0.699,24$ & $0.26 \pm 0.23$ & \multirow{2}{*}{0.0118} \\
\hline & & $>0.699,7$ & $0.55 \pm 0.32$ & \\
\hline
\end{tabular}

duration (in days) of RD. The model (Table 3) explains $85.3 \%$ of the variability of postoperative VA in patients without PVR $\left(R^{2}=0.853,(P<0.0001)\right.$. Following the model, postoperative logMAR VA $=-0.151+0.06$ preoperative duration (in days) of RD. This formula indicates that 8 month-postoperative logMAR VA (with a coefficient of -0.151 ) decreases vision by 0.06 units per each day of increase in preoperative duration of RD.

Patients with PVR IR-ET-1 levels in SRF (pg/ml) and preoperative logMAR VA were effective explanatory variables for postoperative logMAR VA in this group of patients with RD.

Postoperative logMAR VA $=-1.071+0.06$ SRF IR-ET$1(\mathrm{pg} / \mathrm{ml})+0.459$ preoperative logMAR VA (see Table 3 ). The predictive power of this model was $89.9 \%$ $\left(R^{2}=0.899,(P<0.0001)\right.$, meaning that SRF levels of IR-ET-1 $(\mathrm{pg} / \mathrm{ml})$ and preoperative logMAR VA explain $89.9 \%$ of the variability of postoperative VA 8 months after surgery. The last, with a coefficient of -1.071 , means that VA decreases 0.06 units for each $\mathrm{pg} / \mathrm{ml}$ increase of SRF IR-ET-1 and by 0.459 units by each unit of increase of preoperative logMAR VA. Figure 1 shows the spatial relationship between the three variables (in their respective units) included in this model. The plane inside the figure visually represents the combined behaviour of the variables SRF IR-ET-1 $(\mathrm{pg} / \mathrm{ml})$ and preoperative logMAR VA to explain the postoperative logMAR VA (at 8 months) in this group of RD patients with PVR.

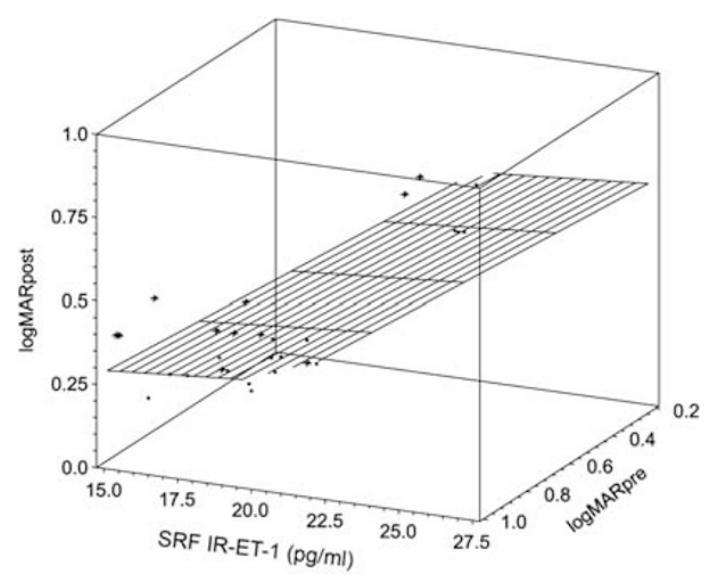

Figure 1 A three-dimensional Maple graphic showing the spatial relationships among three variables: postoperative (8 months) logMAR VA, SRF levels of IR-ET-1 (pg/ml), and preoperative $\log$ MAR VA. The plane inside the cube represents the equation of the model for postoperative (8 months) logMAR VA in proliferative vitreoretinopathy $\left(R^{2}=0.899,(P<0.0001)\right.$. The plane visually represents the combined behaviour of the variables SRF IR-ET-1 (pg/ml) and preoperative logMAR VA to explain the postoperative ( 8 months) logMAR VA. The estimation of the postoperative ( 8 months) logMAR VA is the value of the plane corresponding to the pair of values of the explanatory variables of the model. Eyes with higher values of preoperative logMAR VA than estimated are represented by an asterisk, and eyes with lower values than estimated are represented by a dot.

When independent variables included in the models were categorised (Table 4), a delay in surgery of more than 3 days in patients without PVR was associated with lower postoperative VA $(P=0.038)$ than with a delay of 
$\leq 3$ days. In patients with PVR, SRF IR-ET-1 levels $>16.6$ $\mathrm{pg} / \mathrm{ml}$ and preoperative logMAR VA $>0.069$ were associated with lower postoperativeVA (higher $\log$ MAR).

\section{Discussion}

This study attempted to develop models explaining the variability in VA (measured in terms of the logMAR) 8 months after retinal reattachment surgery. Explanatory variables have been identified by stepwise multivariate linear regression analysis and showed variability depending on whether patients had PVR. In patients without PVR, explanatory variables included the preoperative duration of RD. In patients with PVR, SRF levels of IR-ET-1 and preoperative logMAR VA were the explanatory variables. Our results show that a significant percentage of the variability in VA after RD can be explained-directly or indirectly-by the duration of preoperative RD.

Previously, reduced blood flow and reduced IOP have been found in patients with RD and PVR compared with individuals with normal eyes. ${ }^{5-7}$ Reitsamer and $\mathrm{Kiel}^{9}$ reported that in rabbits, aqueous humour production becomes blood-flow-dependent when ciliary body blood flow is reduced below a critical level (74\% of normal). Other authors ${ }^{8,25}$ have hypothesised that RD may lower IOP by inducing inflammation and reducing aqueous humour formation. To eliminate the possibility of reduced flow as a consequence of a higher IOP, only patients with IOP $\leq 16 \mathrm{~mm} \mathrm{Hg}$ in both eyes were included in our study.

Several authors have found correlations between lower preoperative IOP, the extent of RD, and the presence of macular involvement. ${ }^{26-28}$ Better preoperative VA, a shorter duration of detachment, fewer involved quadrants, younger age, and a lack of macular involvement with the detachment are important positive prognostic factors for VA. ${ }^{29-31}$

In both groups of patients in our study (those with and those without PVR), the preoperative logMAR VA differed (Table 1) depending on whether the macula was involved. However, in both groups of patients no difference in the 8-month-postoperative logMAR was seen in patients with or without macular involvement. Evidence of pre- or postoperative macular disease (except macular detachment) in OCT was one of the exclusion criteria of our study. Curiously, only one patient presented with persistent submacular fluid postoperatively. All patients in this study underwent encircling surgical procedures. Benson et al ${ }^{32}$ reported that $15 \%$ of patients had persistent submacular fluid after vitrectomy, but none of the seven patients in this report who had combined vitrectomy and SB surgery presented with fluid postoperatively. The role of persistent localised submacular fluid (detected by OCT) after SB surgery for $\mathrm{RD}$ remains controversial. In the report by Benson et al ${ }^{33}$ persistent submacular fluid caused delayed visual recovery in half the patients. However, in a report by Seo et al, ${ }^{34}$ the presence of this fluid did not appear to influence final VA or anatomic attachment. The differences in the preoperative duration of $\mathrm{RD}$ in these studies may explain the different results: Seo et al $\mathrm{l}^{34}$ studied only 'acute' macula-off cases. There is a consensus that visual outcomes may remain unsatisfactory even in cases of purely peripheral detachment with a successful reattachment of the retina. ${ }^{35,36}$ In the subgroup of patients in this study without PVR with macula-on $(n=25)$, Pearson's correlation between the duration of RD before surgery (3.12 \pm 0.93 days) and the 8-month-postoperative logMAR VA $(0.04 \pm 0.05)$ was statistically significant ( $r=0.547, P=0.005)$. This finding suggests a different mechanism than that found in patients in whom the macula is involved (macula-off) where preoperative symptom duration may simply represent the duration of macular detachment.

Our linear regression models show that patients with PVR have more profound circulatory disturbances than patients without PVR. Locally generated ET-1 appears to have an important role in patients with PVR, in whom an increased difference SRF minus plasma IR-ET-1 levels has been found compared with patients without PVR. SRF and plasma IR-ET-1 levels have been correlated in patients without PVR $(r=0.687,(P<0.0001)$ and with PVR $(r=0.742,(P<0.0001)$, suggesting that intraocular IR-ET-1 derives in part from the systemic circulation. However, the slope of the correlation, which is greater in patients with PVR, is consistent with enhanced access of plasma proteins to the eye resulting from a disruption of the blood-ocular barrier.

Intraocular ET-1 concentrations may be higher if ET-1 is produced locally or diffuses into the eye from the retinal or choroidal vascular beds and/or from the RPE cells. There is evidence that the RPE is a source of ET- 1 in the retina. ET-1 synthesis and its secretion have been identified in human RPE cells. The release of ET-1 also increases during blood-retinal barrier breakdown (eg, after tumour necrosis factor- $\alpha$ treatment). ${ }^{37} \mathrm{We}$ previously localised ET-1 with an immunohistochemical analysis of epiretinal proliferative tissue from PVR membranes and reported the secretion of ET- 1 by glial and RPE cells. Furthermore, these membranes may express ETA and ETB receptors. ${ }^{17}$ The vascular upregulation of ETA receptors has been reported in experimental RD, ${ }^{14}$ and the stimulation of these ETA receptors may contribute to the induction of cell proliferation. ${ }^{38}$ 
In patients with RD and PVR, increased ET-1 may be a consequence of tissue hypoxia. Hypoxia induces ET-1 gene expression in ET cells and in certain tumours. ${ }^{39,40}$ and is associated with the wound-healing process that causes scar tissue formation (ie, PVR) as a complication of RD. ${ }^{41}$ It has been reported ${ }^{16}$ that the detachment of the neural retina from the pigment epithelium causes, in addition to photoreceptor deconstruction and neuronal cell remodelling, an activation of glial cells. The reactive responses of Muller and microglial cells are not restricted to detached retinal areas but are also observed in nondetached regions of the porcine retina. ${ }^{16}$ Gliosis may reflect or contribute to the neural degeneration that may explain the impaired recovery of vision observed in human subjects after retinal reattachment surgery. ${ }^{16}$ In our PVR cases, plasma and SRF levels of IR-ET-1 were not significantly correlated with the preoperative duration of RD (Table 2). However, IR-ET-1 levels (plasma and SRF) were significantly higher in patients with PVR (preoperative duration: $7.61 \pm 3.88$ days) than in patients without PVR (preoperative duration: $4.27 \pm 2.43$ days) as shown in Table 1 .

In conclusion, preoperative RD duration in patients without PVR and SRF levels of IR-ET-1 (in turn correlated with the preoperative duration of $\mathrm{RD}$ ), in those with PVR appear to be the best explanatory variables for postoperative variability in VA after surgery for RD. Early surgical repair of RD appears to better preserve VA in patients with RD. Future research will be necessary to know whether prompt primary vitrectomy (to eliminate intraocular peptides) could improve outcomes in patients with RD. In addition, the use of coadjutant pharmacologic therapy may be useful in long-standing ( $>4$ days) RD and/or PVR cases.

\section{Summary}

What was known before

- Visual prognosis after retinal reattachment surgery remains unsatisfactory.

- Preoperative duration of retinal detachment, preoperative VA, preoperative IOP, preoperative ocular haemodynamics, and intraocular peptides levels have been associated with final visual prognosis.

What this study adds

- This paper quantifies - using linear regression models-the influence of these factors on postoperative- 8 months-visual acuity.

- In No PVR preoperative duration can predict postoperative VA, with a surgical delay of 4 days or more postoperative visual result will be worse.

- In PVR endothelin-1 in the sub retinal fluid over $16.6 \mathrm{pg} / \mathrm{ml}$ also will be followed by worse visual results.

- The sooner the better for RD surgery should be the best option for vision.

\section{Conflict of interest}

The authors declare no conflict of interest.

\section{References}

1 Girard P, Karpouzas I. Visual acuity after scleral buckling surgery. Ophthalmologica 1995; 209: 323-328.

2 Salicone A, Smiddy WE, Venkatraman A, Feuer W. Visual recovery after sclera buckling procedure for retinal detachment. Ophthalmology 2006; 113: 1734-1742.

3 James M, O'Doherty M, Beatty S. The prognostic influence of chronicity of rhegmatogenous retinal detachment on anatomic success after reattachment surgery. $A m \mathrm{~J}$ Ophthalmol 2007; 143: 1032-1034.

4 Eshita T, Shinoda K, Kimura I, Kitamura S, Ishida S, Inove $\mathrm{M}$ et al. Retinal blood flow in the macular area before and after scleral buckling procedures for rhegmatogenous retinal detachment without macular involvement. Jpn J Ophthalmol 2004; 48: 358-363.

5 Roldán-Pallarés M, Ossama IA, Contreras E, Hernandez J, Ganado T, Bravo C. Ocular blood flow and characteristics of retinal detachment. Arch Soc Esp Oftalmol 2001; 76: 351-356.

6 Roldán-Pallarés M, Musa AS, Hernandez-Montero J, Rollín R, Bravo-Llatas C, Fernández-Durango R. Retinal detachment and proliferative vitreoretinopathy: ophthalmic artery blood velocities, intraocular pressure and endothelin1. Retina 2008; 28: 111-124.

7 Ossama IA, Roldán-Pallarés M, Bravo C. Retinal detachment: scleral buckling and changes in intraocular pressure. Arch Soc Esp Oftalmol 1999; 74: 123-130.

8 Pederson JE, Mac Lellan HM. Experimental retinal detachment I. Effect of subretinal fluid composition on reabsorption rate and intraocular pressure. Arch Ophthalmol 1982; 100: 1150-1154.

9 Reitsamer HA, Kiel JW. Relationship between ciliary body flow and aqueous production in rabbits. Invest Ophthalmol Vis Sci 2003; 44: 3967-3971.

10 Roldán-Pallarés M, Musa AS, Hernandez-Montero J, Bravo-Llatas C. Preoperative duration of retinal detachment and preoperative central retinal artery hemodynamics: repercussion on visual acuity. Graefes Arch Clin Exp Ophthalmol 2009; 247: 625-631.

11 Polak K, Luksch A, Frank B, Jandrasits K, Polska E, Schmetterer L. Regulation of human retinal blood flow by endothelin-1. Exp Eye Res 2003; 76: 633-640.

12 Haefliger IO, Flammer J, Lüscher TF. Nitric oxide and endothelin-1 are important regulators of human ophthalmic artery. Invest Ophthalmol Vis Sci 1992; 33: 2340-2343.

13 Polak K, Petternel V, Luksch A, Krohn J, Findl O, Polska E. Effect of endothelin and BQ123 on ocular blood flow parameters in healthy subjects. Invest Ophthalmol Vis Sci 2001; 42: 2949-2956.

14 Iandiev I, Uhlmann S, Pietsch UC, Biedermann B, Reichenbach A, Wiedemann P et al. Endothelin receptors in the detached retina of the pig. Neurosci Lett 2005; 384: 72-75.

15 Uckermann O, Uhlmann S, Pannicke T, Francke M, Gamsalijew R, Makarov F et al. Ischemia-reperfusion causes exudative detachment of the rabbit retina. Invest Ophthalmol Vis Sci 2005; 46: 2592-2600.

16 Iandiev I, Uckermann O, Pannicke T, Wurm A, Tenckhoff S, Pietsch UC et al. Glial cell reactivity in a porcine model of 
retinal detachment. Invest Ophthalmol Vis Sci 2006; 47 : 2161-2171.

17 Roldán-Pallarés M, Rollín R, Mediero A, Martínez-Montero JC, Fernández-Cruz A, Bravo-Llatas C et al. Immunoreactive ET-1 in the vitreous humour and epiretinal membranes of patients with proliferative vitreoretinopathy. Mol Vis 2005; 11: 461-471.

18 Roldán-Pallarés M, Musa AS, Bravo-Llatas C, FernándezDurango R. Preoperative duration of retinal detachment and subretinal immunoreactive endothelin-1: repercussion on logarithmic visual acuity. Graefes Arch Clin Exp Ophthalmol 2010; 248: 21-30.

19 The Retinal Society Terminology Committee. The classification of retinal detachment with proliferative vitreoretinopathy. Ophthalmology 1983; 90: 121-125.

20 Machemer R, Aaberg TM, Freeman HM, Irvine AR, Lean JS, Michels RM. An updated classification of retinal detachment with proliferative vitreoretinopathy. Am J Ophthalmol 1991; 112: 159-165.

21 Lieb WE, Cohen SM, Merton DA. Color Doppler imaging of the eye and orbit: technique and normal vascular anatomy. Arch Ophthalmol 1991; 109: 527-531.

22 Guthoff RF, Berger RW, Wrinkler P, Helmke K, Chumbley LC. Doppler ultrasonography of the ophthalmic and central retinal vessels. Arch Ophthalmol 1991; 109: 532-536.

23 Lincoff H, Baras I, McLean JM. Modifications to the Custodis procedure for retinal detachment. Arch Ophthalmol 1965; 73: 160-163.

24 Roldan-Pallares M, Sadiq-Musa A, Rollin R, Bravo-Llatas C, Fernandez-Cruz A, Fernandez_Durango R. Retinal detachment: visual acuity and subretinal immunoreactive endothelin-1. J Fr Ophtalmol 2008; 31: 36-41.

25 Cantrill HL, Pederson JE. Experimental retinal detachment III. Vitreous Fluorophotometry. Arch Ophthalmol 1982; 100: 1810-1813.

26 Burton TC. Preoperative factors influencing anatomic success rates following retinal detachment surgery. Ophthalmology 1977; 83: 499-505.

27 Burton TC, Nour-Iddint TA, Phelps CH. Intraocular pressure in retinal detachment. Int Ophthalmol 1979; 1: 147-152.

28 Ringvold A. Evidence that hipotony in retinal detachment is due to juxtapapillary fluid drainage. Acta Ophthalmol 1980; 58: $652-658$.
29 Salicone A, Smiddy WE, Venkatraman A, Feuer W. Visual recovery after scleral buckling procedure for retinal detachment. Ophthalmology 2006; 113: 1734-1742.

30 Ross WH. Visual recovery after macula-off retinal detachment. Eye 2002; 16: 440-446.

31 Liu F, Meyer CH, Mennel S, Hoerle S, Kroll P. Visual recovery after sclera buckling surgery in macula-off rhegmatogenous retinal detachment. Ophthalmologica 2006; 220: 174-180.

32 Benson SE, Schlottmann PG, Bunce C, Xing W, Charteris DG. Optical coherence tomography analysis of the macula after vitrectomy surgery for retinal detachment. Ophthalmology 2006; 113: 1179-1183.

33 Benson SE, Schlottmann PG, Bunce C, Xing W, Charteris DG. Optical coherence tomography analysis of the macula after scleral buckle surgery for retinal detachment. Ophthalmology 2007; 114: 108-117.

34 Seo JH, Woo SJ, Park KH, Yu YS, Chung H. Influence of persistent submacular fluid on visual outcome after successful scleral buckle surgery for macula-off retinal detachment. Am J Ophthalmol 2008; 145: 915-922.

35 Chisholm IA, McClure E, Foulds WS. Functional recovery of the retina after retinal detachment. Trans Ophthalmol Soc UK 1975; 95: 176-182.

36 Sasoh M, Yoshida S, Kuze M, Uji Y. The multifocal electroretinogram in retinal detachment. Doc Ophthalmol 1997; 94: 239-252.

37 Narayan S, Prasanna G, Krishnamoorthy RR, Zhang X, Yorio T. Endothelin-1 synthesis and secretion in human retinal pigment epithelial cells (ARPE-19): differential regulation by cholinergics and TNF-alpha. Invest Ophthalmol Vis Sci 2003; 44: 4885-4894.

38 Fisher SK, Erikson PA, Lewis GP, Anderson DH. Intraretinal proliferation induced by retinal detachment. Invest Ophthalmol Vis Sci 1991; 32: 1739-1748.

39 Kourembaras S, Marsden PA, McQuillan LP, Faller DV. Hypoxia induces endothelin gene expression and secretion in cultured human endothelium. J Clin Invest 1991; 88: 1054-1057.

40 Bodi I, Bishopric NH, Discher DJ, Wu X, Webster KA. Cell-specificity and signalling pathway of endothelin-1 gene regulation by hypoxia. Cardiovasc Res 1995; 30: 975-984.

41 Campochiaro PA. Pathogenic mechanisms in proliferative vitreoretinopathy. Arch Ophthalmol 1997; 115: 237-241. 